\title{
Leather as a Material for Crafting Interactive and Physical Artifacts
}

\author{
Vasiliki Tsaknaki \\ Mobile Life@KTH \\ Royal Institute of Technology \\ Sweden \\ tsaknaki@kth.se
}

\author{
Ylva Fernaeus \\ Mobile Life@KTH \\ Royal Institute of Technology \\ Sweden \\ fernaeus@kth.se
}

\author{
Mischa Schaub \\ HyperWerk \\ HGK FHNW \\ Switzerland \\ mischa.schaub@fhnw.ch
}

\begin{abstract}
Leather is a material used for the making of artifacts ever since early human history, and which can be used also in contemporary design for various types of interactive and electronic products. In this paper, we present a series of small scale explorations of leather, first as skin close interfaces for physical engagement, and secondly in terms of crafting using hand tools and a laser cutter. We reflect on our experiences along these two strands and discuss future possibilities of leather as a rich material for providing new types of interactive experiences. By discussing emerging topics related to traditional crafting processes and contemporary rapid fabrication with this material, we find a great potential of merging such processes and tools for future interaction design settings.
\end{abstract}

\section{Author Keywords}

Interaction; Leather; Crafting; Laser cutter; Rapid prototyping; Design; Material properties

\section{ACM Classification Keywords}

H5.m. Information interfaces and presentation (e.g., HCI):

Miscellaneous.

\section{INTRODUCTION}

In the recent discourse of interaction design, there has been an increased attention to traditional physical crafts, in relation to modern fabrication techniques and the so called post industrial society $[11,12]$, including practiced Do-ItYourself [5,14] and eco design [2].

In the work presented in this paper, focus will be on the material of leather and its crafting properties for interaction designers. This can be seen as a follow up from works of other researchers within the field who have similarly merged design aspects with crafting and interaction while working with a range of materials. Some of these works have explored making soft textile sensors [21], studies of

Permission to make digital or hard copies of all or part of this work for personal or classroom use is granted without fee provided that copies are not made or distributed for profit or commercial advantage and that copies bear this notice and the full citation on the first page. Copyrights for components of this work owned by others than ACM must be honored. Abstracting with credit is permitted. To copy otherwise, or republish, to post on servers or to redistribute to lists, requires prior specific permission and/or a fee. Request permissions from Permissions@acm.org.

DIS '14, June 21 - 25 2014, Vancouver, BC, Canada

Copyright 2014 ACM 978-1-4503-2902-6/14/06(5) \$15.00.

http://dx.doi.org/10.1145/2598510.2598574 traditional book-binding processes [24], paper-based computing [e.g. 3,6,30] and combining digital technologies with craft materials as a means of bringing new groups of people and skills to technology production [15].

With the word leather, we refer to skin, usually from cattle, which through a series of tanning and post-tanning processes has been converted into a biologically resistant material with improved functional and thermal properties [28]. It was one of the first materials used in ancient history for the crafting of artifacts, ranging from clothes to housing and nomadic equipment, such as saddles, tents and furnishing. To this day leather is still used in a range of utilities and applications that surround us, including accessories that we wear, furnishing, and parts of tools and musical instruments. Indeed, elements of leather are also used to some extent in e.g. headphones and casings of electronic products; however, for being such a ubiquitous material in our environment, leather is still largely unexplored in the domain of interaction design. One of few examples is the subculture of Steampunk and their use of specific materials (wood, brass, copper, and leather) together with contemporary electronics, and how these design practices are documented and shared in the community [29].

With the leather material as our starting point, several questions beg for exploration, the most basic perhaps how such organic materials could be practically used in the design of interactive systems. Within the contemporary settings of interaction design, it is also relevant to explore more generally how traditional crafts become reappropriated and how they can gain new value. What can traditional crafting processes teach us when we embark in, also for us, new types of production processes e.g. fabrication with rapid prototyping machines, or for embedding simple electronics in a leather pressure sensor?

\section{BACKGROUND}

Materials used in design and crafts range from plastics and metallic compounds to 'natural' or organic, each having their unique affordances, qualities and aesthetics. Natural materials are considered the ones that are sustainable, recyclable and biodegradable when disposed [32]. In that sense, there are several discussions around what is considered 'natural', sustainable, or eco-friendly, since 
most materials used nowadays have been engineered to some extent, for example by using special dyes to make leather more durable and waterproof. For us, natural, when referring to leather means not synthetic leather (e.g. plastic imitations), but leather made from animal hide, with its specific limitations and properties in terms of e.g. variable size, thickness, and strength.

In design, fashion and applied arts, leather is valued for its unique visual and tactile properties, as well as for simultaneously being a flexible and sturdy material. Leather used in design today makes references both to primitive and nomadic aesthetics, but also to expensive and luxurious items, such as leather accessories produced by exclusive fashion brands, in comparison to 'cheap', mass-produced, fake skin items. Leather also has complex political connotations. While being embraced as a more sustainable alternative to most other materials with similar properties, it is today often produced using questionable processes causing environmental and animal suffering. However, organic leather, created using slower traditional methods without e.g. chemical tanning, does still exist and is also becoming increasingly popular.

Given that leather is a timeless material that can fit into different contexts, it offers a broad and interesting field for exploring its properties and affordances in contemporary design settings. Leather has been explored mostly by fashion designers for making clothes, accessories or even extreme sculptural garments that belong almost to the realm of art (e.g. Una Burke ${ }^{1}$, Maison Martin Margiela ${ }^{2}$ ). However, there is still much to learn around leather and its properties when crafted with both traditional and more contemporary techniques and tools.

This new direction of merging technology, ubiquitous computing and traditional techniques of production with established knowledge is gaining ground, and is something that several scholars currently seem to see a great potential in. Gross et al. argue that within HCI, researchers are investigating the ways that technology and craft are increasingly being leveraged together, leading to new possibilities of making, interacting, or working with integrity, especially when augmenting traditional practices or materials with contemporary ones [10].

Traditional crafts in this context can be defined as the skilled manipulation of physical materials [23], or a means for logically thinking through senses [17]. Relevant to notions of nostalgia and romanticism, crafts expand in a broad field involving a range of materials and techniques. Several studies have recently investigated similar topics of how traditional materials can be used for hybrid interactive or tangible objects. For instance Schmid et al. [26] explored

\footnotetext{
${ }^{1}$ http://www.unaburke.com

${ }^{2}$ http://www.maisonmartinmargiela.com
}

the possibilities of making curved interactive surfaces using hand-blown glass, to explore expanded possibilities in the field of in-car interfaces. Meese et al. [13] have involved ceramics designers and illustrators to explore novel uses and techniques for visual pattern recognition. Several scholars have similarly conducted tests and exploratory design work using interactive electronics combined with materials such as paper [e.g. 3,6], wood (e.g. [31]), and different types of textiles [e.g. 21,22].

Other relevant directions within the field describe the process of crafting from a perspective of pointing out how the crafted artifact reveals specific 'hidden' qualities, as in the case of book binding described by Rosner [24], where 'sensitivities to delicacy, flexibility and delay emerge through detailed engagement with the book' (p. 1155). Others investigate how historical tools and crafting practices can provide new insights to interaction design, such as the possibility of using more complex mechanical structures, rich materiality and whole-body interaction [4].

In parallel to the interest in traditional crafting techniques, there has recently been much research around new possibilities that rapid prototyping tools can offer to the broader understanding of contemporary interaction design. Some examples are Mueller et al. 's work on how folded or bended hard plastics objects could be fabricated using a laser cutter [16], or Fischer et al.'s project on using a 3D printer for constructing the casing of a device [5].

With fabrication, we here refer to concrete manufacturing using various techniques, from the use of hand tools to rapid prototyping machines, such as laser cutters, 3D printers or CNC cutters. Until recently, the fabrication process was primarily referring to mass production of goods within factories, an idea that changed due to technical and social developments, which have brought attention also to local, small scale, and even personal fabrication. Examples include online communities that allow for extensive sharing of instruction and advice (e.g. Instructables ${ }^{3}$ and $\mathrm{KOBAKANT}^{4}$ ), together with the availability of new types of software and hardware tools for local production.

A related trend is the rapid spread of Fab Labs in several cities worldwide, described by Gershenfeld as 'the combination of commercially available machines and parts, linked by specific developed software and processes, for making things' [9, p. 12]. This has opened a new design space for small-scale production, since expensive machines and tools now become available for citizens to use, either free of charge, or at a lower cost. Easy and quick access to personal fabrication equipment has now enabled designers as well as amateur makers to explore a range of physical shapes of interactive artifacts, while producing more

\footnotetext{
${ }^{3} \mathrm{http}: / / \mathrm{www}$. instructables.com

${ }^{4}$ http://www.kobakant.at
} 
prototypes or finalized products in less time. By this shift in production methods, the number of iteration circles during a design process has increased, which can possibly improve the design process itself and subsequently the quality of the final product.

All these trends indicate that there is currently a growing interest in engaging with so-called 'natural' materials, and many design practitioners and researchers are investigating their potentials, not only in physical-, but also in digitaland interaction design practices. Bridging technology with materials, Vallgårda and Redström [30] regard material properties as a different starting point for exploration in interaction design that offers new possibilities. Following on this approach, the topic of this paper is the materiality of both traditional and digital making, focusing on leather and its unique properties as a material to craft with.

\section{OVERVIEW OF THE STUDY}

The design explorations presented in this paper took place both in Basel and Istanbul, where they have been emerged and developed, as part of a project called motoco (http://motoco.me), initiated and run by HyperWerk Institute for Postindustrial Design. The project is a longterm multi-disciplinary collaboration between designers and design students from different countries, examining the potential of creating mobile design networks and building a common vocabulary of design tools and methods. The resulting artifacts from this study were designed for, and later exhibited at, the DMY International Design Festival in Berlin.

Apart from the particular explorations presented in this paper, the project included a series of sessions exploring leather in design and interaction, where items such as handles, cases for iPads and glass holders were fabricated (see Figure 1).

For the context of this paper, focus will be on how leather and its physical properties affected the way the artifacts were crafted, using both hand tools and a laser cutter.

The paper is divided in two sections. In the first section (Part 1) we present the sound box, a simple interactive table made out of wood, leather and electronics. Describing the process of crafting the table's interactive interface we discuss topics that became apparent to us when combining leather with computational components in design. This part of the study took form during a collaborative workshop with students from Yildiz Technical University in Istanbul, where particular elements of nomadic design concepts were developed. This workshop consisted of five students enrolled in the Media Technology program, who contributed mostly during the initial brainstorming sessions, while the first author, having a background in Product and Interaction Design, was responsible for making the actual interactive sound box.

In the second section (Part 2) we elaborate further on crafting with leather as such, by presenting the process of designing and fabricating a series of functional parts of spatially expanding support structures for the final exhibition design. We present and describe the fabrication of one particular type of such leather items, first by using hand tools in a 'traditional' leather crafting process, and later by using a laser cutter. The first and the third author initiated the explorations with the laser cutter, since they had already some experience with leather crafting.

To our help in all this work was also an experienced leather craftsman, who ran an old leather-crafting workshop near our research lab, and was an important source of advice and recommendations at different stages of the design and crafting process. Another helpful source of inspiration and knowledge related to leather and its possible uses for crafting different utilities and accessories, was an old catalogue from a former suitcase company [20].

\section{PART 1: CRAFTING AN INTERACTIVE SOUND BOX}

In this section we will present the sound box, a simplistic interactive table constructed out of leather, wood and electronic components. Since this project was implemented in Turkey, we chose to integrate elements of the cultural feature of traditional Turkish tea ceremonies into the design. The basic idea was that this table could be an alternative and temporary space, where people could gather,
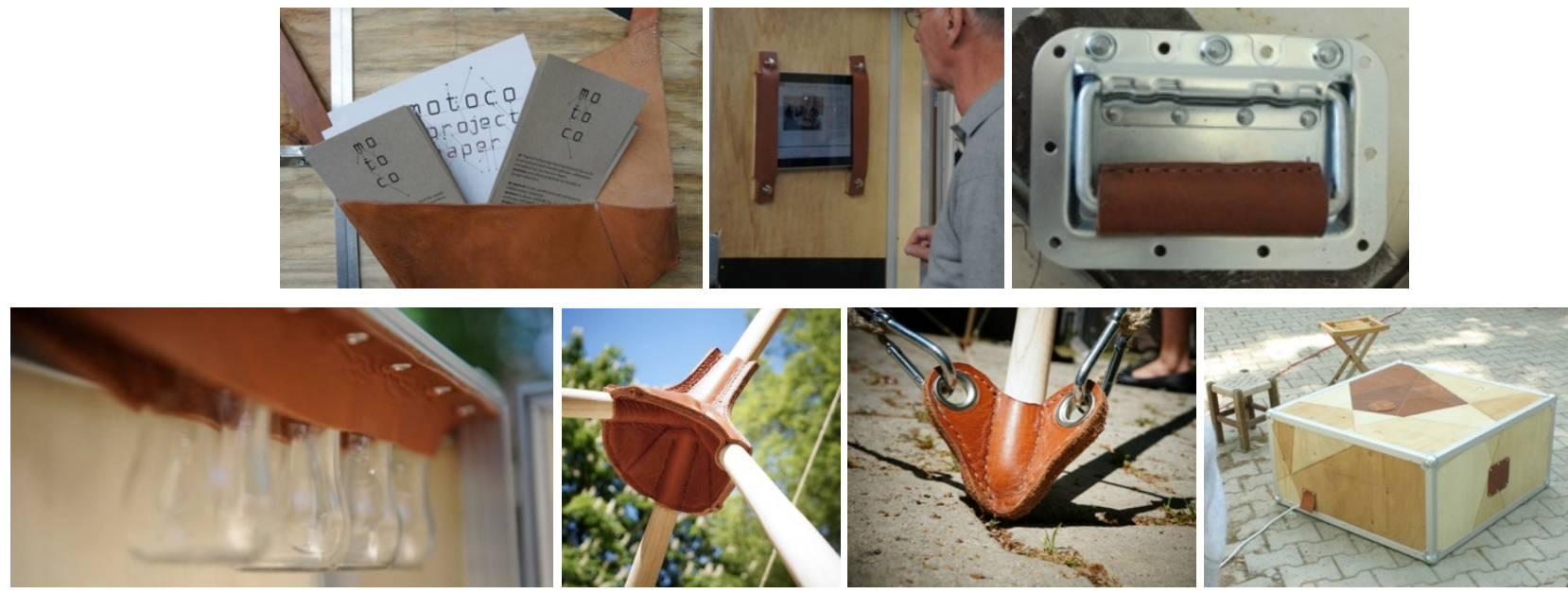

Figure 1. Examples of leather artifacts designed during the presented study. From top left: (a)a holder for information leaflets about the project, (b)iPad holders, (c)handles for mobile furniture, (d)holders for glasses used in Turkish tea ceremonies, (e, f)support structures for spatially expanded exhibition elements (described in Part 2 below), and (g)an interactive sound box (described in Part 1 below). 
socialize and explore its interactive properties, while hearing fragments from our experiences in Turkey.

The size of the box was $100 \mathrm{~cm} x 100 \mathrm{~cm}$ and its height $50 \mathrm{~cm}$, similar to the common low tea tables that we experienced in Istanbul. Interactive tables of similar formats have been explored before, but usually with a table top screen display [7], or with a focus on particular interactive qualities [18]. Here, however, focus is on our experiences from the crafting process related to leather as a material that could be used in interactive artifacts, rather than on how tabletop surfaces can serve as generic interactive interfaces. This was our first exploration on how such materials could be combined when making interactive objects, where leather could serve as a skin-close interactive interface.

The functionality of the sound box itself was highly simplistic. The top surface of the box was covered in an asymmetrical pattern of leather pieces (based on the visual identity of the project), and divided into five press-sensitive areas functioning as 'pushbuttons', each triggering a recorded sound file to play. The reason why we chose simple tactile input for triggering the audio ('pushbuttons') was in order to explore how leather could be used as a material for skin-close interaction. After placing the big leather piece on the top of the wooden construction, it was the actual quality of leather itself (softness and thickness) that led us craft the buttons on its actual surface. In this process, we followed a discreet visual and tactile language for interaction, varying only the texture of the 'button' areas while leaving the smooth, original leather texture on the non-interactive ones. To create these changes on the leather surface we used different leather crafting tools, scratching every 'button' and thus giving to each area a different texture and thereby also a colour shade (Figure 2). Another 'pushbutton' area in the shape of a circle functioned as stop button. To process the sound files and control the inputoutput we used Arduino and Processing open software. The digital hardware used for the interactive part was placed inside the box, consisting of a laptop, an Arduino Uno microcontroller, and a pair of speakers.

The leather surface used for the interactive interface was measured and cut by hand tools, in order to make a perfect fit to the space where the wood had been previously removed (Figure 2). This process required much precision in both calculating the dimensions and cutting the leather piece, since the wood and leather should fit nicely one next to the other to create a smooth surface. The main challenge was to craft both a good-looking smooth surface, but also a robust and reliable interactive interface.

\section{Crafting Pressure-sensitive Sensors Using Leather}

For making the 'pushbutton' sensors using leather as the external pressure-sensitive surface, we took inspiration from how common textile pressure sensors are crafted. Starting from that point, we used knitted conductive fabric, conductive thread and cables [see e.g. 20]. Two conductive fabric pieces were used for each 'button' area, one placed on the backside of the leather surface and the other placed on a thick cardboard surface facing the leather, which was added just for this purpose (Figure 2).

However, in contrast to pressure sensors made out of fabric, we quickly learnt that leather and its specific affordances made it slightly different when used for similar applications. When using leather to craft a pressure sensor, as in the example presented here, there is a need to adapt

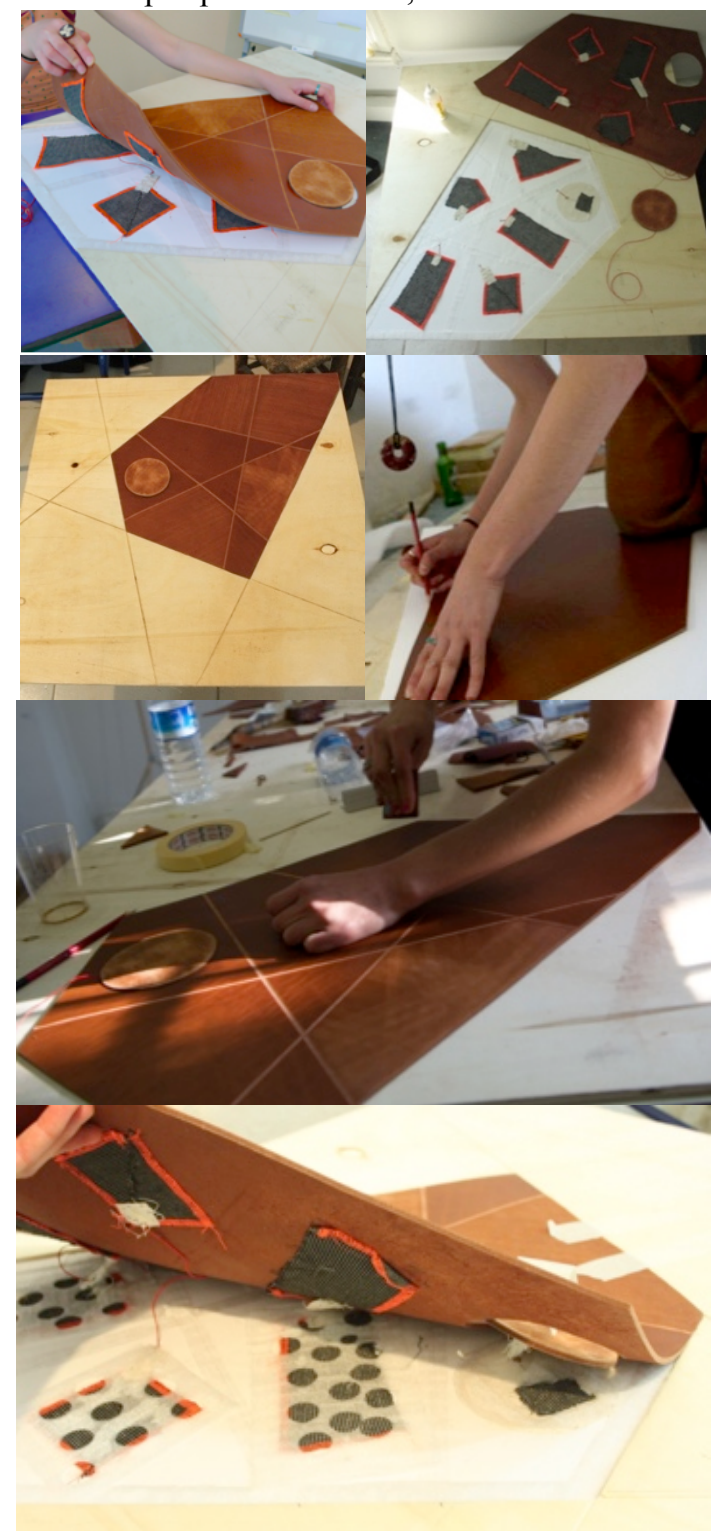

Figure 2. Different stages of making the pressuresensitive buttons for the interactive sound box.

previous knowledge of similar examples - mostly with soft materials - in accordance to the properties of leather.

In the case of the sound box we used leather with a thickness of $4 \mathrm{~mm}$, which is considered to be relatively thick and sturdy, and the reason for this was mainly driven by aspects of construction, specifically the need to combine 
wood and leather of the same thickness. However, due to the overall weight of the leather surface hosting the pressure-sensitive sensors, a slight pressure was applied continuously to them. Even though the decision to cut a big leather surface, instead of cutting separate leather surfaces for each one of the 'pushbuttons' was taken for reasons related to construction and visual properties, the same result would not have happened if other materials had been used, such as neoprene or thick fabric. The quick solution for this problem was to add a spongy plastic material with holes between the two sides of each sensor, in order to eliminate the sensitivity of each sensor area, caused by the applied weight of the leather surface. Even though more pressure was needed afterwards for triggering the audio, the overall interactive interface was more robust and responsive to interaction. However, a technically robust interface is not always enough when it comes to interaction.

Since the interface and interaction was so simple, the idea was to let visitors at the exhibition explore and discover on their own how to use and play with the sound box (Figure 3). However, during the five days of the exhibition, we noted how visitors instead of readily treating the interface as 'pushbuttons', often started off by gently touching and stroking the surface. Part of this could be due to the ambiguous design of the interface, but it also seemed like the material as such invited this type of manipulation, perhaps due to a curiosity of touching the leather, to feel its texture and quality. The result was that it became harder than we had imagined for visitors to discover the interactive qualities of the sound box and how to initiate the interaction. The main problem was that in this specific design the pressure sensors under the leather surface were triggered by applying force, rather than touch. In a later exploration we replaced the textile pressure sensors with capacitive sensors under wooden or leather surfaces, triggered by slight touch, instead of pressure. This proved to be much more successful in terms of interaction and more 'natural', in terms of the interactive affordances of these specific materials.

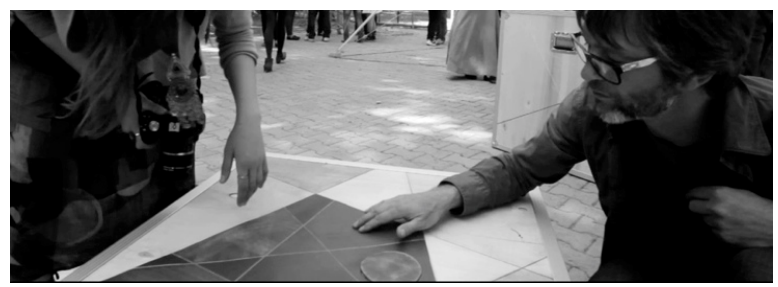

Figure 3. Exploring the interactive properties of the sound box, during the DMY International Design Festival in Berlin, 2012.

\section{Reflections on Leather as a Skin-Close Interface}

Flexibility, one of the properties of leather, makes it appropriate to be used as a pressure-sensitive interface, similar to soft 'textile-ish' materials such as neoprene, felt or foam. On the other hand, the degree of flexibility depends on the thickness, the type and the leather qualities to be chosen depending on the needs of each project and context of use.

Some questions that arose during this process regarding the use of leather for crafting interactive artifacts:

Could a leather surface be engineered to some extent in order to acquire conductive properties? Instead of using a leather surface only as an external casing, where the electronic qualities are hidden under its surface, the actual material could potentially be enhanced to be the one bearing responsive properties, e.g. by combining it with conductive ink, thread and other substances. That would be opposed to the simple placing of a leather surface in front of a conductive one (as presented in the example with the pressure-sensitive sensors), by crafting a material composite consisting of leather and a layer of conductive material, for example.

Regarding a systems' input/output, where leather is used for the physical interface: Since leather is not broadly used for designing interactive artifacts, there is still a lot to be learnt regarding its affordances in relation to a system's functionality. For example we saw that leather could be used when designing for stroking rather than pushing, to trigger an interactive behaviour. For even richer interactive experiences some kind of tactile feedback could be included in interactive leather objects, in order to further address the observed interest in touching and stroking the surface.

Using the physical properties of leather when crafted ('crafting properties'), in order to integrate leather in interactive artifacts. Since it is difficult to cut and stich on a leather surface (especially when thick leather is used), the laser cutter is a valuable tool for forming physical interactive leather objects. We also noted that the material could be engraved either with hand tools or with a laser cutter, or make it blend with other physical materials, catering for unique interactive experiences.

\section{PART 2: CRAFTING LEATHER ARTIFACTS}

In this section we elaborate further on crafted artifacts using leather, first using hand tools (as a traditional leather crafting process), and later on by using a laser cutter for designing and cutting the leather patterns. In these processes, we designed and constructed a series of custommade 'joints', used as central elements for hosting and holding together a number of wooden poles (Figure 1e) and Figure 4f) and 'corners', used for knotting and tightening ropes at the edge of each wooden pole (see Figure 1f and Figure 4d). Both leather items were used as functional parts of spatially expanding support structures in our design exhibitions, as shown in Figure 4e.

\section{Process of Crafting Leather Using Hand Tools}

When constructing these artifacts, the first step was to measure the thickness of each wooden pole belonging to a construction, which would be inserted into the holes of the final leather object. The perimeters of each of the three poles were measured and then a two dimensional sketch 
was drawn on a paper, out of the three-dimensional shape the leather part should have.

As the next step, the 'spreaded' pattern was transferred on a leather surface and cut (Figure $4 \mathrm{~b}$ ). In this stage, before cutting the leather, additional material should be calculated around the 'spreaded', two-dimensional shape, for making easier the sewing process that follows. Specifically, the additional leather was needed both for making the holes to
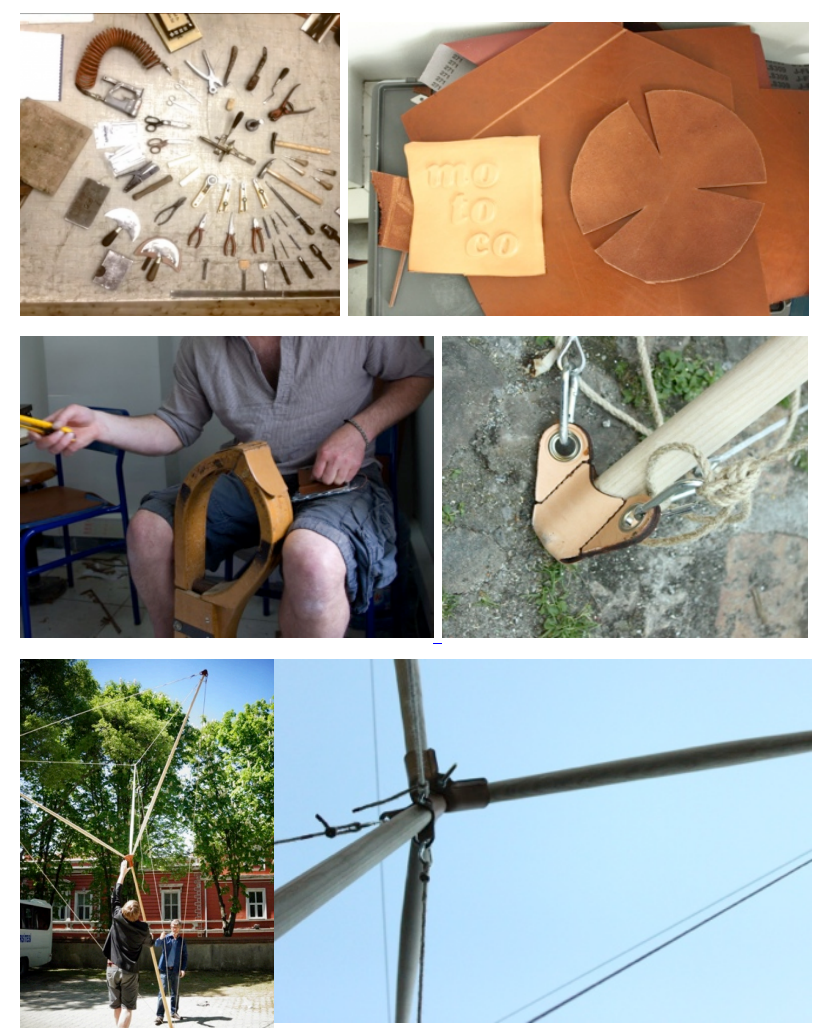

Figure 4. (a)Special tools for leather handcrafting, used in the presented explorations, (b)2D leather shape cut out for crafting, (c)using a 'stitching horse' for transforming a $2 \mathrm{D}$ leather surface into a 3D form, (d)(e)(f)leather 'corners' and 'joints' crafted as functional parts of spatially expanding support structures for design exhibitions.

insert the needles and for holding the leather artifact stable in the 'stitching horse', while sewing. At the end of the process, any additional leather material can be cut out, or folded. According to the advice given by the experienced craftsman, it is better to calculate and cut in advance a bigger leather surface than the one needed, because of the difficulty to predict exactly the $3 \mathrm{D}$ form produced by a $2 \mathrm{D}$ leather surface.

When it comes to the stage of transforming the twodimensional surface into a three-dimensional 'sculptural' form, the neighbouring sides are sewn together. An old 'stitching horse' was used for stabilizing the leather piece during the sewing process, which was done using two thick needles, special for leather sewing and strong, waxed yarn (Figure 4c). For connecting the neighbouring sides together by hand sewing, each hole for inserting the needles would be made in advance with an awl hand tool. This could be avoided when thin leather was used, but in this specific context the thickness of the leather was $5 \mathrm{~mm}$, which was chosen on purpose to be fairly thick in order for the sewn leather objects to be rigid and keep the construction parts in place. Alternatively, the sewing process can be done with a special sewing machine for leather, which was not available in this design setting.

What makes any hand crafting process special is the fact that the final crafted artifact is always unique and somewhat different from what was expected at the beginning. Even when the exact dimensions of the desired crafted artifact were well defined at an initial design stage, additional aspects that appeared during the crafting process would affect how the final item would look or function. In our design setting, while constructing the leather 'corners' and 'joints', some of the aspects that affected the process were the hand stitching, the innate flexibility of leather, foldings and pleats made on the leather surface and additional adaptations and decisions taken throughout the crafting process.

\section{Process of Crafting Leather Using a Laser Cutter}

A different approach to making the above type of leather items, was to use a laser cutter as part of the leather crafting process. During these explorations we used the 'Lasersaur', an open source laser cutter, assembled and operated in our workshop space.

One obvious aspect that made this process different compared to handcrafting was that some parts of the process, which were previously done by hand and using hand tools, were now performed using a laser cutter. Specifically, the sketch was drawn on a computer using 3D modelling software (Rhinoceros ${ }^{6}$ ), which is compatible with the laser cutter model. In our experience, this 'automatized' fabrication process saved much time compared to handcrafting the leather artifact, and sketching pieces manually on paper. However, it demanded more time to be spent on the early stages of thinking and designing how the final leather item should look and function, before sending the 2D drawing for cutting. A reflection to this observation is that crafting in this setting can be considered the detailed and thoughtful sketch on the modelling software, whereas traditionally crafting referred to the manipulation of a material only by hand.

Another relevant aspect of this process was the fact that the holes for sewing could be drawn at the same time as the two-dimensional sketch and thereby also cut by the laser

\footnotetext{
${ }^{5} \mathrm{http}: / /$ labs.nortd.com/lasersaur/

${ }^{6}$ http://www.rhino3d.com
} 


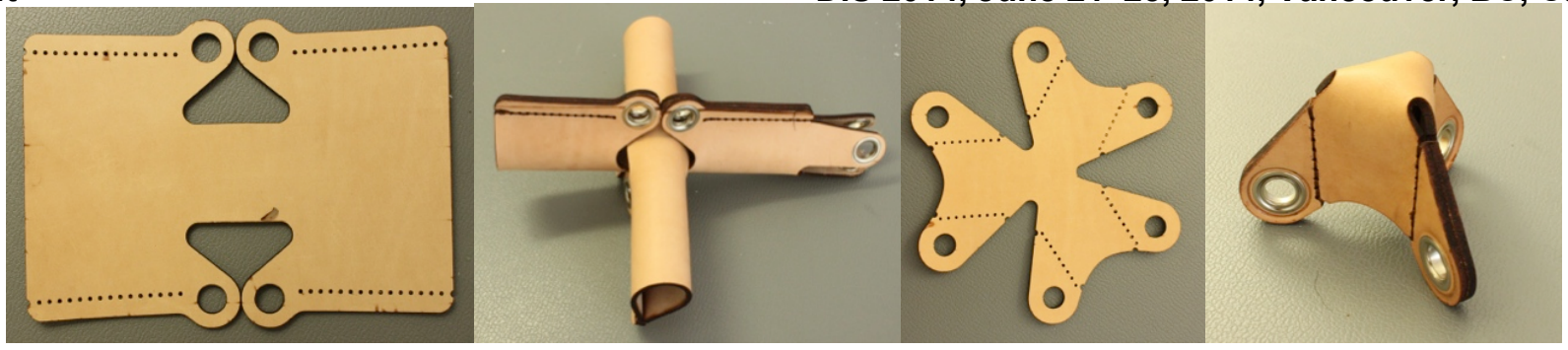

Figure 5. Examples of holes created by the laser cutter, and how this supported sewing and construction of physical shapes.

cutter, instead of opening each hole by hand, later on in the process. Sewing was made by hand in a similar way as described above, using waxed yarns and two needles, while holding the leather form stable on the 'stitching horse'. An interesting observation was that the two-dimensional leather shape cut with the laser cutter was much easier to sew since its form and the already-opened holes were reflecting how to connect the sides and therefore transformed it more easily into a three-dimensional object. In different stages of the design process, when there was a need to test ideas quickly, alternative solutions were used for making 3D leather functional parts and placing them in a construction. Since sewing is a time consuming process, we crafted a series of leather items with wider holes, where plastic cable binders could be inserted for holding the neighbouring leather sides closed, instead of sewing the sides permanently with thread. Therefore a three-dimensional shape could be assembled much more quickly out of a twodimensional leather surface, after drawing the holes in the software and cut by the laser cutter (Figure 6).

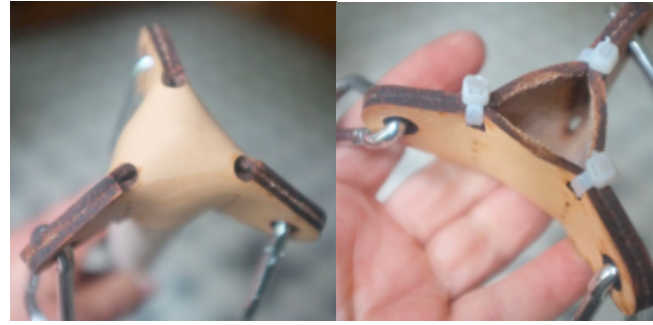

Figure 6. Plastic cable binders were used instead of sewing for making leather prototypes quicker.

\section{'Adjusting' Techniques Used in Leather-crafting}

The fact that an experienced leather craftsman took part in our explorations, was important for us in order to observe and learn some of the 'adjusting' techniques used to solve problems occurring in different stages of the leather crafting process. This included for example practices of adjusting an artifact's shape or size, instead of cutting a new one, when the result was not the one expected. We learnt that this is an important part of leather crafting, not only because the high price of leather, but also for reasons related to traditional ideals of re-use and repair, as opposed to just starting over and making new whenever something goes 'wrong'.

One technique that we tried was to soak the leather in water, which makes it more flexible, and malleable, and thus possible to mould, stretch or form into different shapes. For example it is possible to fold or bend it in different directions and even create a cast, by stretching it around a three-dimensional object. The benefit of using this technique is that when the leather becomes dry and hard again, it stays in the form given when wet.

To speed up the drying process (which can take up to 12 hours), and with lack of information how this could be done, we experimented by 'baking' the leather object in a microwave oven. Specifically, we wanted to test if one of the leather joints used for our exhibition structure could shrink and become more rigid and hard. However, the result of this experiment was not successful, as the leather object became hard as plastic and deformed. Other common 'adjusting' techniques are additional sewing or gluing, for example to make the parts of a leather object tighter or smaller. All these techniques, we believe, will be useful to know of when designing interactive artifacts using leather, although these specific explorations concerned the making of non-interactive physical artifacts.

\section{DISCUSSION}

In this paper we have aimed to present some explorative designs, where leather was the material in focus. Based on our experiences from these cases, we will here discuss issues that we found especially interesting with respect to our general research questions:

- What are the affordances of leather in the context of interactive artifacts, and what properties of leather are necessary to consider in such contexts?

- What can be learnt in the intersection of traditional crafting processes and contemporary fabrication with rapid prototyping machines, for the making of interactive technology?

- How can traditional crafts be re-appropriated and gain value in contemporary crafting and interaction design settings?

\section{The Interactive Affordances of Leather}

The physical properties of leather are familiar to us mainly from everyday interaction with products in our surrounding such as bags, clothes, seat covers, to name a few. Additionally, an established knowledge base exists related to leatherwork as a crafting technique and hobby, with specifically designed tools and developed use practices, as 
documented in several books [e.g. 8,27]. However, crafting a pressure sensor out of conductive materials and leather, as well as using a laser cutter to craft hybrid leather objects are design practices for which there were not much available references or information at the time of this study (conducted in 2012). Therefore, the process and the engagement with the material itself opened up new perspectives and revealed some of leather's crafting properties, but also its interactive affordances.

Our experience is that leather as a material may invite people to engage in a different way, compared to plastics or textiles for example. Although this is essentially just a matter of 'surface', and core interactive properties still reside in the electronic behaviour, such aspects may fundamentally affect interactions and relationships with and around the designed artifact. This became especially clear to us in the public display of the interactive sound box. The material affordances of stroking rather than pushing came as a surprise to us and made us reconstruct the whole interface after the exhibition. The affordance of stroking also opens up for other potentially interesting use cases that would be suitable for leather, e.g. to embed tactile or haptic feedback into interactive leather items.

Organic materials also lend themselves to crafting in other ways than more 'industrialized' materials such as plastics. This affected for instance the way we designed symbolic patterns as buttons by carving or engraving on the leather surface. When using leather as a skin-close interface for interaction, the 'front' or external surface could be engraved in different ways, which can be an important aspect for creating a distinct visual identity of a specific interactive object, as was the case in the design of the sound box. Moreover, when using thick leather, it is possible to carve out (remove) some of the material's thickness and create space for example behind a surface, where electronics and cables could be hosted. This is possible by using either hand tools or a laser cutter.

We also found the fact that leather is at the same time soft and flexible, as well as sturdy and strong, to be an interesting property for further exploration in the context of interactive artifacts, for example to incorporate it into flexible or foldable displays.

But considering leather as a material that could offer new possibilities for future interaction design contexts, additional explorations and studies could be initiated around already constructed uses, meanings, and techniques with this material, beyond the level of considering only its physical affordances [10].

\section{Leather Combined with Electronics}

From a perspective of sustainable design, the short life cycle of electronic products is an issue often brought up [19]. If we accept that most interactive products cannot be expected to last forever, it is relevant to start considering further use of physical materials that might have a shorter life cycle, but that are biodegradable, and possible to produce using environmentally friendly processes. In that sense, leather could be used instead of plastics or other nonbiodegradable materials for designing interactive items, in combination with high-tech electronics.

Some questions that arise include how we can combine leather with electronics. Will we use e-textiles (conductive thread, textiles etc.) or hard electronics (e.g. making metal studs through the material and soldering electronic parts straight onto it)? Since it belongs neither to the category of 'textiles', even though thin leather is used in similar contexts (e.g. by fashion designers), nor to the category of more rigid materials, such as cardboard, plastic or acrylic, there is a broad space of exploring ways to combine it with other materials or electronic components.

Another important aspect concerns the assembling and building of 3D objects out of parts, or 2D surfaces. So far, building digital artifacts has mostly been towards a direction of combining and assembling smaller units or components together, similar to the process of prototyping circuits in a breadboard, where smaller components are added and soldered together. In contrast, in the above presented assembling process, we used a 2D leather surface that could be cut in every possible shape out of a big leather piece and transformed into a 3D form by sewing or connecting the neighbouring sides together. This process resembles the fashion design process, when in order to make a 3D shape (garment) you follow a similar process of cutting a $2 \mathrm{D}$ shape out of a surface and then creating the $3 \mathrm{D}$ form by sewing it. We are wondering whether it could be possible to follow a similar approach for building interactive, electronic artifacts in the future? How would it be for example, to have a big 2D surface with embedded electronics, microchips and circuits and from that to cut imaginative shapes, e.g. with a laser cutter. This could, again, be especially relevant with the recent advent of bendable computer screens and other developments in computer hardware.

\section{Combining Traditional and High-tech Crafting Techniques}

Rapid prototyping tools such as laser cutters open up the design and fabrication space by providing new possibilities, for example to cut a material surface in the most imaginative shapes and with exact precision. Taking this field of new possibilities further, when such tools and processes can be combined with traditional crafting techniques, there seems to be an interesting and unexplored design space for both physical and interactive artifacts.

But since this design and production space is still fairly new, a series of questions arise on how such tools can be used, to what extent, or what their possibilities and limitations may be. In our case we were especially struck by how crafting techniques with long and established traditions came to enhance and enrich our more contemporary design activities using high-tech tools. As the design and research world 
expands towards new directions, there is a need for sharing and articulating such 'hybrid' design processes.

In our explorations with the laser cutter our aim was not to give details on how to use this tool for crafting leather in the most efficient way, for example what would be the speed value or depth the laser beam should have for cutting a leather surface of specific thickness without burning its surface (which depends on the specific type of leather and machine used). Instead, by presenting two different leathercrafting approaches we aim at exploring 'traditional' crafting techniques using only hand tools in contrast to contemporary fabrication processes in interaction design settings, when working with leather.

For example, in the process of using the laser cutter, we had to go through a number of design iterations, necessary for learning how this tool could be best used with the specific material of leather, for making a particular design (in our case leather corners and joints). This was a new field of exploration for us, as well as for the experienced leather craftsman, where we had to face a series of unexpected and new design challenges. Since the use of specific tools affects the way a material can be crafted, involving a laser cutter in a leather-crafting process can be seen as a new tool to craft such material. This changes not only the way traditional leather crafting is approached and practiced, but it also implies different crafting properties of leather.

An important difference between handcrafting processes and the processes with the laser cutter was that the former allowed the development of the form and design of the artifact to develop while making it. When using a laser cutter, it was necessary to imagine and know the shape, size and dimensions of the final three-dimensional object in advance, since it needs to be drawn in real scale, before cutting it with the machine. For this reason, it seems that elements of handcrafting are still necessary and helpful in initial design stages of exploring a shape and form that an artifact should have. The use of a laser cutter thereby became most useful in a later design stage, where more artifacts should be made with already tested dimensions, and in less time.

Leather crafting has a long tradition in terms of how to use specific materials and how to proceed in the crafting process. Much time is required, not only to learn and practice a specific technique at an initial stage, but also to craft every single object. For an experienced craftsman this slow exploration of an object's form is a normal part of the process, of the 'dialogue' with the material being crafted, which leads to different feedback and reflection loops that are unique in every similar design process and setting.

In contrast, as product and industrial designers, and perhaps even more so interaction designers, we are often used to follow a different process, based more on a concept and design idea than the qualities and 'language' of the material being used, unfolding while crafting. Additionally, it is widely known that the contemporary high-speed nature of life is rubbing off to design and production as well. This is something which tends to be contradictory to everyday aesthetics [1] and craft.

We are curious how new types of crafting practices will emerge in the future, when professional crafts such as leather-crafting, could be taught and practiced together with contemporary crafting of electronics.

\section{CONCLUSION}

In this paper, we have presented several examples of working with leather, and discussed the properties of this material in terms of interaction, electronics design, and for crafting using both traditional hand tools and modern laser cutters. Our main motivation for conducting this study was that there are not yet many reported examples, either in the interaction- or product design field, where leather is used as a material for making physical or interactive artifacts using modern techniques and toolkits. To combine the functionality of interactive artifacts with the particular aesthetics and crafting properties of leather opened an interesting and new design space for us, which hopefully will inspire future work in the area of natural and organic materials in the development of interactive products. Our main findings concerned the interactive affordances of leather and the crafting properties in terms of electronics, traditional hand tools, and the use of a laser cutter.

\section{ACKNOWLEDGMENTS}

The practical part of this project was conducted as part of the motoco project, initiated by HyperWerk Institute for Postindustrial Design. Core of the writing and analysis was conducted as part of the Arts and Crafts project at Mobile Life VinnExcellence Centre, with a grant from Vinnova. We thank all participants in the workshops in Basel and in Istanbul, as well as visitors in the final exhibition, for providing valuable input to this work.

\section{REFERENCES}

1. Bardzell, S., Rosner, D.K., and Bardzell, J. Crafting quality in design: integrity, creativity, and public sensibility. DIS '12, ACM Press (2012), 11-20.

2. Blevis, E. Sustainable interaction design: invention $\&$ disposal, renewal \& reuse. $C H I$ '07, ACM Press (2007), 503:512.

3. Buechley, L., Hendrix, S., and Eisenberg, M. Paints, paper, and programs: first steps toward the computational sketchbook. TEI'09, 2009, 9-12.

4. Fernaeus, Y., Jonsson, M., and Tholander, J. Revisiting the Jacquard Loom: Threads of History and Current Patterns in HCI. CHI'12, ACM (2012).

5. Fischer, P.T., Hornecker, E., and Zoellner, C. SMSlingshot: an expert amateur DIY case study. TEI '13, ACM Press (2013), 9-16. 
6. Gardiner, M. and Gardiner, R. The functional aesthetic of folding, self-similar interactions. TEI '12, ACM Press (2012), 19.

7. Gaver, W.W., Bowers, J., Boucher, A., et al. The drift table: designing for ludic engagement. $\mathrm{CHI}$ '04, ACM Press (2004), 885-900.

8. Geoffrey, W. Leatherwork: A Manual of Techniques. The Crowood Press Ltd, 2005.

9. Gershenfeld, N. Fab: The Coming Revolution on Your Desktop--from Personal Computers to Personal Fabrication. Basic Books, 2008.

10. Gross, S., Bardzell, J., and Bardzell, S. Structures, forms, and stuff: the materiality and medium of interaction. Personal and Ubiquitous Computing, (2013).

11. Kumar, K. From Post-Industrial to Post-Modern Society: New Theories of the Contemporary World. John Wiley \& Sons, 2009.

12. Malpas, S. The Postmodern. Routledge, 2005.

13. Meese, R., Ali, S., Thorne, E.-C., et al. From codes to patterns: designing interactive decoration for tableware. CHI '13, ACM Press (2013), 931-940.

14. Mellis, D.A. and Buechley, L. Case studies in the personal fabrication of electronic products. DIS '12, ACM Press (2012), 268-277.

15. Mellis, D.A., Jacoby, S., Buechley, L., PernerWilson, H., and Qi, J. Microcontrollers as material: crafting circuits with paper, conductive ink, electronic components, and an "untoolkit."TEI '13, ACM Press (2013), 83-90.

16. Mueller, S., Kruck, B., and Baudisch, P. LaserOrigami: laser-cutting 3D objects. CHI'13, ACM Press (2013), 2585-2592.

17. Nimkulrat, N. Hands-on Intellect: Integrating Craft Practice into Design Research. International Journal of Design 6, 3 (2012), 1-14.

18. O'Hara, K. Interactivity and non-interactivity on tabletops. Proceedings of the 28th international conference on Human factors in computing systems - CHI '10, ACM Press (2010), 2611-2614.

19. Odom, W., Pierce, J., Stolterman, E., and Blevis, E. Understanding why we preserve some things and discard others in the context of interaction design. CHI '09, ACM Press (2009), 1053-1062.
20. Openwerk. Nomadic Gear Catalogue. 2012. http://openwerk.net/NomadicGearCatalogue.pdf.

21. Perner-Wilson, H., Buechley, L., and Satomi, M. Handcrafting textile interfaces from a kit-of-noparts. TEI '11, ACM (2010).

22. Persson, A. Exploring textiles as materials for interaction design. 2013. http://bada.hb.se:80/handle/2320/12221.

23. Rosner, D.K. and Ryokai, K. Reflections on craft: probing the creative process of everyday knitters. C\&C ’09, ACM Press (2009), 195-204.

24. Rosner, D.K. and Taylor, A.S. Antiquarian answers: book restoration as a resource for design. CHI '11, ACM Press (2011), 2665-2668.

25. Saul, G., Xu, C., and Gross, M.D. Interactive paper devices: end-user design \& fabrication. TEI'10, 2010, 205-212.

26. Schmid, M., Rümelin, S., and Richter, H. Empowering materiality: inspiring the design of tangible interactions. TEI '13, ACM Press (2013), 91-98.

27. Stohlman, A. The Art of Hand Sewing Leather. Andy Leather Co, 1977.

28. Sureshkumar, P.S., Thanikaivelan, P., Phebe, K., Krishnaraj, K., Jagadeeswaran, R., and Chandrasekaran, B. Investigations on Structural, Mechanical, and Thermal Properties of Pineapple Leaf Fiber-Based Fabrics and Cow Softy Leathers: An Approach Toward Making Amalgamated Leather Products. Journal of Natural Fibers 9, 1 (2012), 37-50.

29. Tanenbaum, J., Tanenbaum, K., and Wakkary, R. Steampunk as design fiction. $C H I$ '12, ACM Press (2012), 1583.

30. Vallgårda, A. and Redström, J. Computational composites. CHI'07, ACM (2007), 513-522.

31. Vallgårda, A. PLANKS: 569-574. NordiCHI '08, ACM Press (2008), 569-574.

32. Wegst, U.G.K. and Ashby, M.F. The mechanical efficiency of natural materials. Philosophical Magazine 84, 21 (2004), 2167-2186.

33. Zhu, K. and Zhao, S. AutoGami: a low-cost rapid prototyping toolkit for automated movable paper craft. $C H I$ '13, ACM Press (2013), 661-670. 